\title{
Patients' Lived Experiences of Nocturia: A Qualitative Study of the Evening, the Night, and the Next Day
}

\author{
Andrew Trigg ${ }^{1} \cdot$ Fredrik L. Andersson $^{2}$ Natalie V. J. Aldhouse ${ }^{1} \cdot$ \\ Donald L. Bliwise $^{3} \cdot$ Helen Kitchen ${ }^{1}$
}

Published online: 19 April 2017

(C) The Author(s) 2017. This article is an open access publication

\begin{abstract}
Background Nocturia, waking to urinate two or more times during the night, is a chronic condition associated with significant patient burden due to sleep disruption. This study aimed to explore the lived experiences of patients with nocturia in terms of the disruption to their lives during the night and day.

Methods Adult patients in the US diagnosed with nocturia were recruited for face-to-face qualitative interviews. Thematic analysis of patients' narratives, taking a phenomenological interpretative approach, summarised their experiences throughout the night and day, including any apparent contrasts between patients.
\end{abstract}

Electronic supplementary material The online version of this article (doi:10.1007/s40271-017-0241-0) contains supplementary material, which is available to authorized users.

Helen Kitchen

hkitchen@teamdrg.com

Andrew Trigg

atrigg@teamdrg.com

Fredrik L. Andersson

fredrik.andersson@ferring.com

Natalie V. J. Aldhouse

naldhouse@teamdrg.com

Donald L. Bliwise

dbliwise@emory.edu

1 Clinical Outcomes Assessment, DRG Abacus, Manchester, UK

2 Global Health Economics and Outcomes Research, Ferring Pharmaceuticals A/S, Copenhagen, Denmark

3 The Emory Program in Sleep, Emory University, Atlanta, GA, USA
Results Twenty patients (10 male, 10 female) aged between 39 and 80 years, averaging three night-time voids, were interviewed. Analysis revealed that nocturia has a substantial impact on sleep quality and quantity, with the frequency of night-time voids a key driver of this. In addition to night-time phenomena, patients faced various difficulties the next day, including day-time tiredness, lack of energy and concerns related to emotional wellbeing, social functioning and cognitive functioning. All of these limited patients' capacity to work, perform daily activities or fulfil role responsibilities. Patients' lifestyles influenced experience, where younger patients in employment more readily emphasised the day-time physical and psychosocial burdens. Patients employed coping behaviours in an attempt to lessen the severity of nocturia and its impact, which were both physician-led and self-taught.

Conclusions While the symptom of nocturia only occurs during the night, the impact is longer lasting, affecting functioning and wellbeing throughout the following day. Patients' circumstances can affect the extent of their burden; recognising this can improve effective delivery of patient-centred care. 


\section{Key Points for Decision Makers}

- Nocturia, a chronic condition, negatively impacts sleep quality, sleep quantity, overall quality of life and work productivity. This is especially true for those urinating twice or more during the night.

- Nocturia is more common in older patients ( $\geq 65$ years) and previous research has focused on this age group. This study found that day-time burden was more apparent in younger, employed participants than older, retired participants.

- The qualitative evidence in this study demonstrates that while the symptom of nocturia only occurs during the night, the impact is longer lasting. The patient experience changed according to the time of day, with three distinct phases: evening, night, and the next day. Detailed accounts of participants' experiences provide a new perspective to understanding the burden of nocturia.

\section{Background}

Nocturia has been defined as a condition where individuals must wake at night one or more times to urinate, where each void is preceded and followed by sleep [1]. However, the need to urinate at least twice during the night has been suggested as a more clinically relevant definition, as two voids per night is the frequency at which nocturia generally becomes bothersome for patients [2,3]. Nocturnal polyuria (NP) is the leading cause of nocturia and is defined as abnormally excessive urination during the night $(>33 \%$ of urine production in 24 hours in elderly individuals) [1, 4].

Nocturia is the most common cause of sleep disruption, being more common than other causes of sleep disturbance in older adults such as physical pain, night-time heartburn, thirst and noise $[2,5,6]$. Accordingly, nocturia is significantly associated with both self-reported and objective measures of sleep quality [5, 7]. The resulting chronic compounding sleep disruption leads to decreases in overall health-related quality of life, reduced cognitive performance, decreased work productivity and impaired activities [3, 8-11]. Indeed, the extent of work productivity impairment due to nocturia appears comparable to that of other more frequently researched chronic conditions including chronic obstructive pulmonary disease, arthritis and depression [11]. Notably, these detriments are experienced during the daytime, indicating a constant burden of nocturia in patients' lives.
The prevalence of nocturia increases with age, with up to $60 \%$ of people aged over 70 years voiding at least twice per night [12]. As such, the majority of previous nocturia research has been conducted in an older population $[2,5,7]$. However, the prevalence of at least two nightly voids within males and females aged between 20 and 40 years is as high as $16.6 \%$ and $18 \%$, respectively [12].

The aim of this research was to explore in depth the lived experiences of patients with nocturia in terms of the disruption to their lives during the night and day. In particular, this study focused on the lesser documented daytime experience of people with nocturia. In addition, this study aimed to explore the experiences of individuals ranging in age and social roles, with the goal of identifying any similarities or differences in experience according to these demographic variables.

\section{Methods}

A total of twenty patients with a diagnosis of nocturia due to NP were recruited. The study was approved by the New England Independent Review Board (NEIRB), reference number 16-058.

\subsection{Participants}

English-speaking participants were recruited from two geographically disparate sites within the US: Midwest and South. Each participant was recruited according to prespecified eligibility criteria via referral from clinicians who treat and manage patients with nocturia due to NP. Patients aged at least 18 years, with a clinician-confirmed diagnosis of NP, experiencing an average of at least two voids per night for the previous 2 weeks, and with no concomitant genitourinary illnesses responsible for urgency or urinary incontinence were eligible (for full eligibility criteria see the Additional file 1, Table 1 in the electronic supplementary material). Participants were provided with an informed consent form (approved by the NEIRB), which had to be understood and signed prior to any data collection.

Purposive sampling was employed (Table 1) to ensure demographic diversity and that the sample was representative of patients affected by nocturia due to NP. The targeted sample size was guided by previous experience and published suggestions [13], but was confirmed via data saturation analysis. Additionally, the regions for recruitment were selected to enhance cultural and geographic diversity within the sample. Note that a range of ages was a particularly important target, both in recognition that nocturia is more common in people aged 65 years and over [12], and that the experience of younger patients 
Table 1 Purposive sampling targets

\begin{tabular}{lll}
\hline Quota & $\begin{array}{l}\text { Minimum number to target } \\
\text { in the sample }(n=20)\end{array}$ & $\begin{array}{l}\text { Number achieved in } \\
\text { the sample }(n=20)\end{array}$ \\
\hline $\begin{array}{l}\text { Age (year) } \\
<50\end{array}$ & 4 & 5 \\
$\geq 65$ & 4 & 12 \\
Gender & & \\
Male & 10 & 10 \\
Female & 10 & 10 \\
Ethnicity & & \\
Non- & 4 & 7 \\
Caucasian & & \\
patients & & \\
Education & & \\
High school \\
diploma or \\
less
\end{tabular}

( $<50$ years) is less well documented. This ensured that each age group was represented in the sample and that any differences in experience between these groups could be explored.

Participants who met all the study eligibility criteria and fitted the targeted characteristics for study sampling were invited to participate in a face-to-face interview at a date and time convenient to them.

\subsection{Interviews}

A semi-structured interview guide was used to conduct each interview, comprising open-ended questions and follow-up probes to encourage discussion of relevant issues in an unbiased and spontaneous way (see Table 2). All interviews were conducted by an experienced qualitative interviewer (AT) at a research facility in Chicago or New Orleans between March 23, 2016 and March 30, 2016 and lasted $60 \mathrm{~min}$ each. Participants' lived experiences of nocturia were discussed for approximately $20 \mathrm{~min}$; the remainder of time was spent discussing patient-reported outcome measures, the results of which are not reported here. After each interview, participants were remunerated US\$125 for their time.

\subsection{Analysis}

Demographic and clinical characteristics, collected during recruitment, were descriptively summarised. Interviews were audio-recorded and transcribed verbatim; interviewer notes capturing non-verbal cues were also collected. The qualitative data were subject to thematic analysis, aided through the use of ATLAS.ti v7.5 software. The analysis took a phenomenological interpretative approach, seeking to understand the multiple realities of participants rather than one 'true' reality, and focusing on the perceptions, feelings and lived experiences of participants [14]. Codes were assigned to phrases within the transcripts summarising the core meaning of participants' narratives, from which themes were identified. These themes were then compared and contrasted in order to interpret structure among them, both within participants and between participants according to clinical or demographic characteristics.

Data saturation analysis is a hallmark of robust qualitative research; providing an indication of breadth and depth of understanding and guiding sample size requirements [15]. Data saturation was explored to evaluate the adequacy of the sample size and the extent to which findings from the interviewed participants are generalisable to the population of patients with nocturia due to NP. Participants were divided chronologically into three sets. The themes that emerged in each set were compared with the next in the form of a data saturation grid (Additional File 1, Table 2, see electronic supplementary material) to help identify the point of saturation, defined as the point at which no new relevant information emerged and once the research team had achieved a rich level of understanding [15].

\subsection{Reflexivity}

The influence of researchers' preconceptions, attitudes or characteristics on data collection, analysis and interpretation was acknowledged. FA and DB have both published

Table 2 Example open-ended questions and follow-up probes

Can you tell me about the most recent night that you needed to urinate in the night, in between the time you went to bed at night with the intention of sleeping, and the time that you woke up in the normal way to start your day the next morning?

1. What happened between going to bed and getting up for the day the next morning?

2. How long after going to bed with the intention of sleeping did you wake up because of the urge to urinate?

3. Tell me about how you woke up the next morning

Can you take me through an average night-time for you?

1. What happens between going to bed and getting up for the day the next morning?

2. Is it easy or difficult to fall asleep? Tell me about that

3. Is it easy or difficult to stay asleep? Tell me about that 
previous research on the association between nocturia and reduced quality of life, and thus would have assumed that this would be demonstrated in this study. Therefore, the interviewing and analysis were conducted by AT, NA and HK, who had less prior knowledge of nocturia and could therefore employ a more inductive approach. Interviewer effects due to race, gender and age are documented [16]; however, none of the topics raised in the interview were deemed particularly sensitive, and the use of one interviewer (AT), experienced in qualitative interviewing, helped to keep such error constant. Additionally, the researchers' decision to employ purposive sampling and explore demographic differences may have unduly created the notion that such differences would exist between patients.

\section{Results}

Participant demographic and clinical characteristics are presented in Table 3; all purposive sampling targets were met (Table 1). Data saturation was achieved, as demonstrated by the data saturation grid in Additional file 1, Table 2 (see electronic supplementary material).

\subsection{Main Themes}

The patient experience of nocturia changed according to the time of day, with three distinct phases: evening, night and the next day.

\subsubsection{Evening}

In the evening, anticipation built around the forthcoming nightly struggle and behaviour was moderated in an attempt to reduce the frequency of night-time voids. Such coping behaviours were often as a result of advice directly administered by their primary care physician:

"I cut down liquids, you know like you tell a baby or a child, you can't have something past whatever so they won't wet the bed or something." (Female, 41)

Following such advice caused subsequent patient-led coping mechanisms, such as reducing food consumption in the evening, as "you're thirsty if you eat" (Female, 65). Additionally, participants sometimes stayed up later to effectively reduce the duration of sleep within which disruptions could occur:

"by eight o'clock at night I'm exhausted. I'm tired enough to go to sleep but if I go to sleep I'll be up more during the night ... [the frequency] depends on when I go to sleep." (Female, 73)
Table 3 Participant demographic and clinical characteristics

\begin{tabular}{|c|c|}
\hline Participant characteristics & $n=20$ \\
\hline \multicolumn{2}{|l|}{ Gender, $n(\%)$} \\
\hline Male & $10(50)$ \\
\hline Female & $10(50)$ \\
\hline Age, year, mean (range) & $64(39-80)$ \\
\hline \multicolumn{2}{|l|}{ Ethnicity, $n(\%)$} \\
\hline Caucasian/White & $13(65)$ \\
\hline African American/Black & $7(35)$ \\
\hline \multicolumn{2}{|l|}{ Education, $n(\%)$} \\
\hline High school, but no diploma & $1(5)$ \\
\hline High school diploma or equivalent & $8(40)$ \\
\hline College or associate degree & $4(20)$ \\
\hline Graduate degree & $7(35)$ \\
\hline \multicolumn{2}{|l|}{ Employment, $n(\%)$} \\
\hline Working full-time in paid job & $7(35)$ \\
\hline Working part-time in paid job & $2(10)$ \\
\hline Looking for work & $1(5)$ \\
\hline Full-time homemaker & $2(10)$ \\
\hline Retired & $8(40)$ \\
\hline \multicolumn{2}{|l|}{ Living situation, $n(\%)$} \\
\hline Living with partner and children & $10(50)$ \\
\hline Living with partner & $6(30)$ \\
\hline Living alone & $2(10)$ \\
\hline Living alone with children & $1(5)$ \\
\hline Other & $1(5)$ \\
\hline Months since diagnosis, median (range) & $17(7-69)$ \\
\hline \multicolumn{2}{|l|}{ Number of nightly voids, $n(\%)^{\mathrm{a}}$} \\
\hline 2 & $3(17)$ \\
\hline $2-3$ & $3(17)$ \\
\hline 3 & $7(39)$ \\
\hline $3-4$ & $1(6)$ \\
\hline 4 & $1(6)$ \\
\hline $4-5$ & 0 \\
\hline 5 & $1(6)$ \\
\hline $5-6$ & $2(11)$ \\
\hline \multicolumn{2}{|c|}{$\begin{array}{l}\text { Current nocturia treatment prescribed by physician, } \\
n(\%)^{\mathrm{b}}\end{array}$} \\
\hline Diuretics & $4(20)$ \\
\hline Limitation of fluid intake & $10(50)$ \\
\hline Feet elevation & $2(10)$ \\
\hline Bladder control & $1(5)$ \\
\hline Exercise & $4(20)$ \\
\hline None & $10(50)$ \\
\hline
\end{tabular}

${ }^{a}$ Data only available for 18 participants. Some participants expressed their responses as a range. Percentages are expressed as the percentage of participants with data available. Percentages do not add to $100 \%$ due to rounding

b Participants could have been prescribed more than one treatment 


\subsubsection{Night}

In accordance with the International Continence Society guidelines on nocturia, night was interpreted as the period of time between going to bed with the intention of sleeping and waking with the intention of arising [1]. As expected, all participants described frequent urination at night, the defining symptom of nocturia. Participants reported their first void as between 1 and 3 hours after going to bed, preventing them from reaching a "deep sleep".

"I get up two or three times a night to go to the bathroom ... It's not good because I need 8 hours sleep a night... it's a pain in the neck when you get up two or three times a night and have to go back to sleep three times ... it's not restful sleep." (Male, 58)

"having to go to the bathroom every 2 hours. It irritates me no end." (Female, 78)

Most distinguished a 'good night', 'average night' and 'bad night' based on the frequency of urination. Generally, a good night comprised one or two urinations, an average night comprised three urinations and a bad night comprised four urinations. Understandably, this varied across participants depending on severity; one participant described a good, average and bad night as one, two and three respective voids, whilst another described three, four and six voids. Another reported waking to urinate up to seven times on his worst nights.

Nocturia impaired sleep in terms of quantity, "I don't get as much sleep as I possibly can" (Male, 39), and in terms of quality, "sometimes I can fall back asleep but it's not the same rest as before, it's like a lower degree" (Male, 53). Indeed, not getting enough sleep or experiencing broken sleep was the most bothersome aspect of nocturia for over a third of patients interviewed. Sleep quantity was further reduced by "a hard time falling [back] asleep once I'm up" (Female, 75), and such difficulties often caused participants to arise for the day earlier than they would have wished: "another hour or half hour, depending how long it takes me to fall back asleep, what's the point?" (Male, 39).

Wider impacts on participants' social and emotional wellbeing were also experienced. Sleeping away from home was met with reluctance due to possible embarrassment and inconvenience in visiting the toilet in different surroundings. One participant also felt guilty for waking their partner when frequently getting up during the night.

\subsubsection{The Next Day}

Unsurprisingly, lack of sleep caused tiredness the next day:

"I'm tired all the time. I'm tired right now... [The problem is] not the act of having to get out of bed and go to the bathroom, the problem with the whole thing is that you're really tired all of the time." (Female, 65)

In addition to the core tiredness, and in many cases linked to this, were multiple wider burdens for participants during the day. Participants were aware of changes in their mood due to lack of sleep, feeling "cranky", "grumpy", or "moody". An inability to concentrate or focus following a bad night's sleep was also described: "it really messes with your concentration" (Female 39). Participants' mood, inability to concentrate, and a "lack of energy" or feeling "drained" had consequences on their ability to work:

"If I have a business meeting or I have to meet clients it's very difficult, it's more difficult to concentrate." (Male, 58)

"They call me grumpy at work. ...I go into the back room and I don't want to be talking to them, I'm tired." (Female, 41)

In addition to paid employment, tiredness affected work as a homemaker or caring for relatives, including role requirements such as driving:

"If you're sleepy you're not going to be able to drive, especially if you've got a kid, you're not going to be doing some things. Some people drive like that but I'm not [going to drive] when I'm tired. Certain things you're just not going to do." (Female, 41)

Participants' social lives were also affected by the tiredness resulting from nocturia, in terms of difficulty interacting with others due to mood changes, or less enthusiasm to socialise:

"I went with [my friend] yesterday to [the department store], and we walk in and I'm looking and I swear it must be 10 miles long, and I look and I said, 'I know I can walk there, I just don't think I can walk back, I'm too tired.' So instead I sat in the shoe department and waited for her." (Female, 75)

Many participants reported napping or resting during the day as a coping mechanism to deal with poor sleep at night. In fact, several participants in full-time employment were forced to take naps during the workday; one participant even declined to eat during her lunch break to accommodate it. Two also described falling asleep uncontrollably, which, if at work, caused worries over job security:

"I go to work sometimes and I'm working and I'm just like asleep, and it's because of [the nocturia] so you know what I'm saying? So sometimes I'll be like oh Lord, don't fire me I'll have to tell you what's really going on with me because I'm not partying or 
nothing, I just don't get any sleep, and that's just so annoying to me." (Female, 39)

\subsection{Similarities and Differences in Experience Across Patients}

Younger, employed participants reported day-time burden more frequently than older, retired participants. All but one of the participants not reporting any tiredness the next day were retired rather than working, and therefore may have had more flexibility in sleep patterns and fewer compulsory daytime tasks. Of those who took naps during the day, the majority were retired, full-time homemakers, looking for work, or working part time, who again are likely to have increased flexibility in their routines compared with full-time employees. Additionally, participants with young children and subsequent role responsibilities reported greater impairment during the daytime. Notably, those with responsibility for caring for younger grandchildren also reported similar effects. Table 4 compares the narratives of two participants differing in age, employment status and role responsibilities.

\section{Discussion}

A greater depth of understanding has been gained regarding patients' lived experiences of nocturia. Data saturation indicates that an adequate sample size was recruited and the findings provided rich insight into the burden of people with nocturia due to NP. The division of experience into evening, night and the next day provides a novel framework through which to appreciate the burdens of patients with nocturia. Participants' descriptions of the impact of two or more nightly voids supported previously suggested thresholds defining bothersome nocturia [2, 3]. As a result of multiple night-time voids, participants' sleep quality was reduced, again in line with previous findings [5, 7]. The reported daytime impairments in health-related quality of life, concentration, activities and work productivity also provide additional depth to previous similar findings [3, 8-11, 17]. Furthermore, the replication of previous findings also conducted through qualitative methodology [17] strengthens the validity of our understanding of patient burden in this field.

Reduced work productivity due to nocturia was an important part of many patients' experience in this study. It has previously been estimated that the annual cost of lost productivity due to nocturia (two nightly voids) in the US is US\$61 billion [18]. This substantial cost highlights the importance of identifying those patients likely to have reduced work productivity, in order to provide tailored care.

Clinical expert opinion and observational data indicates that currently, inadequate recognition and diagnosis of nocturia, leading to inappropriate treatment, is a major barrier to sufficient care $[19,20]$. There is also an ongoing

Table 4 Differences in experience due to age and employment status: a comparison between two cases

\footnotetext{
Case study 1: John*

John, aged 39, typically wakes up three times during the night to urinate. The most bothersome aspect during the night is the difficulty he has in falling back to sleep after urination, which reduces the hours of deep sleep:

"not getting enough sleep ... it takes me maybe a minute to go and use the washroom, that's not that bad. Just what bothers me the most is after that, going to lay down and maybe taking an hour to fall back asleep"

As a result of this, upon waking for work the next day, John often experiences lapses in his productivity, and difficulties maintaining a good mood:

"I kind of drag my feet, I'm a little lazy and everything, a little grumpy ... I'm not as productive at work"

Once returning home, he is exhausted and must take a nap, affecting his ability to complete household and family duties, and his relationship with his family:

"coming home and my wife telling me "Go take out the garbage", and I' $m$ too tired because I had a bad night's sleep ... So I put stuff off, or I'm supposed to take my kids to their activities, and I fall asleep and try to take a nap, whatever, and they don't wake me up and they miss their stuff and everything. I guess it's not just affecting me, it's affecting my whole family ... they [also] notice the difference in mood and the way I feel"
}

\section{Case Study 2: Mark*}

Mark, aged 80, typically wakes up three to four times during the night at consistent intervals:

"if I go to bed at eight or eight-thirty, by eleven or eleven-thirty I'm up. I go back to bed, two-thirty or quarter to three I'm up, five-thirty or quarter to six I'm up [again], and normally I just stay up. If I go back to bed [in] a couple of hours I'm up again"

This disruption is reduced depending on the timing at which he drinks during the preceding day:

"it depends on what I drink during the day. Say I drank my water early in the morning, usually by the time I go to bed I can [sleep] maybe four or five hours [uninterrupted]. But I do have to get up [eventually]"

Despite the frequent disruption to his sleep, which he attributed to his old age, Mark did not describe feeling tired or any impairment of activities the next day. Because Mark is retired, he feels able to cope with his sleep disruption by resting when required:

"the next day is about the same ... this is my age, I probably don't need as much sleep as a person that works all day ... I don't have a whole lot to do in the daytime so if I want to sit down and rest I can sit down and rest"

\footnotetext{
* Pseudonyms have been used to protect the identity of the individuals reporting their experience
} 
discussion as to whether the overactive bladder (OAB) diagnosis is too all-encompassing and reliant on symptomatology, leading to a high level of misdiagnosis for nocturia patients [21]. One study demonstrated that over $60 \%$ of patients with nocturia received antimuscarinics and/or $\alpha$-blockers (recommended for lower urinary tract symptoms [LUTS] and OAB), whereas only $16 \%$ used desmopressin as recommended [19, 20, 22]. Also, $<50 \%$ of patients diagnosed with nocturia had been diagnosed by completing a voiding diary as recommended [20]. The findings of this study will hopefully help increase the recognition of nocturia and its burden, leading to adequate diagnosis and treatment. Another interesting finding was the patient-led coping mechanisms employed beyond the advice of a physician [20]. The full extent and effectiveness of these warrants further exploration.

Limitations of this study are acknowledged. Firstly, as the study was conducted in the US only, the findings of this research may not be generalisable to other countries and cultures. Furthermore, qualitative inquiries can be influenced by researchers' personal biases; however, a reflexivity process was employed throughout the study in an attempt to mitigate this.

\section{Conclusions}

While the symptom of nocturia only occurs during the night, the impact is longer lasting, affecting functioning and wellbeing throughout the following day. Patients' circumstances, especially employment status, can largely affect the extent of their burden. Recognising the above, the development of new treatments and the acknowledgement of existing treatments by primary care physicians could improve the effective delivery of patient-centred care. Additionally, these qualitative findings strongly parallel the data observed in numerous other quantitative studies.

Acknowledgements The authors acknowledge Nicki Hoskins of DRG Abacus for medical writing support.

\begin{abstract}
Author contributions AT contributed to study concept and design, data collection, data analysis, interpretation of results and drafting of the manuscript. He also acts as overall guarantor of this work. FA contributed to study concept and design. NA contributed to data analysis and interpretation of results. DB contributed to interpretation of results. HK contributed to study concept and design, data analysis, interpretation of results and drafting of the manuscript. All authors contributed to the review, critical revision and final approval of the manuscript.
\end{abstract}

\section{Compliance with ethical standards}

Conflict of interest HK, AT and NA are employees of DRG Abacus, a healthcare research company that consults with various pharmaceutical and biotechnology companies. FA is an employee of Ferring, which markets treatments for nocturia. DL is a consultant to Ferring and Merck.

\section{Consent for publication Not applicable.}

Ethics approval and consent to participate The study was approved by the New England Independent Review Board (NEIRB), Reference Number 16-058. Participants were provided with an informed consent form (approved by the NEIRB), which had to be understood and signed prior to any data collection.

Funding Funding for this work was provided by Ferring Pharmaceuticals $\mathrm{A} / \mathrm{S}$.

Availability of data and materials The interview transcripts are not publicly available to protect participant confidentiality, but the openended discussion sections of the interview transcripts are available from the corresponding author on reasonable request.

Open Access This article is distributed under the terms of the Creative Commons Attribution-NonCommercial 4.0 International License (http://creativecommons.org/licenses/by-nc/4.0/), which permits any noncommercial use, distribution, and reproduction in any medium, provided you give appropriate credit to the original author(s) and the source, provide a link to the Creative Commons license, and indicate if changes were made.

\section{References}

1. van Kerrebroeck P, Abrams P, Chaikin D, Donovan J, Fonda D, Jackson S, Jennum P, Johnson T, Lose G, Mattiasson A, et al. The standardisation of terminology in nocturia: report from the Standardisation Sub-committee of the International Continence Society. Neurourol Urodyn. 2002;21:179-83.

2. Bing MH, Moller LA, Jennum P, Mortensen S, Skovgaard LT, Lose G. Prevalence and bother of nocturia, and causes of sleep interruption in a Danish population of men and women aged 60-80 years. BJU Int. 2006;98:599-604.

3. Tikkinen KA, Johnson TM 2nd, Tammela TL, Sintonen H, Haukka J, Huhtala H, Auvinen A. Nocturia frequency, bother, and quality of life: how often is too often? A population-based study in Finland. Eur Urol. 2010;57:488-96.

4. Abrams P, Cardozo L, Fall M, Griffiths D, Rosier P, Ulmsten U, van Kerrebroeck P, Victor A, Wein A. The standardisation of terminology of lower urinary tract function: report from the Standardisation Sub-committee of the International Continence Society. Neurourol Urodyn. 2002;21:167-78.

5. Bliwise DL, Foley DJ, Vitiello MV, Ansari FP, Ancoli-Israel S, Walsh JK. Nocturia and disturbed sleep in the elderly. Sleep Med. 2009;10:540-8.

6. Ohayon MM. Nocturnal awakenings and comorbid disorders in the American general population. J Psychiatr Res. 2008;43:48-54.

7. Obayashi K, Saeki K, Kurumatani N. Quantitative association between nocturnal voiding frequency and objective sleep quality in the general elderly population: the HEIJO-KYO cohort. Sleep Med. 2015;16:577-82.

8. Holm-Larsen T, Albei C, Andersson F, Nørgaard JP. 405 'My sleep pattern is a series of naps'. Subjective patient-reported data on what is most bothersome about nocturia. Eur Urol Suppl. 2013;12:e405-6.

9. Andersson F, Anderson P, Holm-Larsen T, Piercy J, Everaert K, Holbrook T. Assessing the impact of nocturia on health-related 
quality-of-life and utility: results of an observational survey in adults. J Med Econ. 2016;19:1200-6.

10. Ancoli-Israel S, Bliwise DL, Norgaard JP. The effect of nocturia on sleep. Sleep Med Rev. 2011;15:91-7.

11. Miller PS, Hill H, Andersson FL. Nocturia work productivity and activity impairment compared with other common chronic diseases. Pharmacoeconomics. 2016;34:1277-97.

12. Bosch JL, Weiss JP. The prevalence and causes of nocturia. J Urol. 2010;184:440-6.

13. Guest G, Bunce A, Johnson L. How many interviews are enough? Field Methods. 2006;18:59-82.

14. Guest G, MacQueen KM, Namey EE. Applied thematic analysis. Newcastle upon Tyne: Sage; 2011

15. Fusch PI, Ness LR. Are we there yet? Data saturation in qualitative research. Qual Rep. 2015;20:1408.

16. Davis RE, Couper MP, Janz NK, Caldwell CH, Resnicow K. Interviewer effects in public health surveys. Health Educ Res. 2010;25:14-26.

17. Booth JM, Lawrence M, O’Neill K, McMillan L. Exploring older peoples' experiences of nocturia: a poorly recognised urinary condition that limits participation. Disabil Rehabil. 2010;32:765-74.
18. Holm-Larsen T. The economic impact of nocturia. Neurourol Urodyn. 2014;33(suppl 1):S10-4.

19. Weiss JP, Blaivas JG, Bliwise DL, Dmochowski RR, DuBeau CE, Lowe FC, Petrou SP, Van Kerrebroeck PE, Rosen RC, Wein AJ. The evaluation and treatment of nocturia: a consensus statement. BJU Int. 2011;108:6-21.

20. Oelke M, Anderson P, Wood R, Holm-Larsen T. Nocturia is often inadequately assessed, diagnosed and treated by physicians: results of an observational, real-life practice database containing 8659 European and US-American patients. Int J Clin Pract. 2016;70:940-9.

21. Drake MJ. Do we need a new definition of the overactive bladder syndrome? ICI-RS 2013. Neurourol Urodyn. 2014;33:622-4.

22. Gravas S, Bachmann A, Descazeaud A, Drake M, Gratzke C, Madersbacher S, Mamoulakis C, Oelke M, Tikkinen KAO. Guidelines on the management of non-neurogenic male lower urinary tract symptoms (LUTS), incl. benign prostatic obstruction (BPO). European Association of Urology. 2014. https://uroweb. org/wp-content/uploads/Non-Neurogenic-Male-LUTS_2705.pdf. 